\title{
Self-reported tobacco use and correlation with umbilical cord blood cotinine levels at delivery among Appalachian gravidas
}

Jesse N. Cottrell, MD ${ }^{1}$, Brenda L. Mitchell, MD ${ }^{1}$, Pooja N. Sangani, MSIV ${ }^{1}$, D’Andrea S. Thomas, $\mathrm{MPH}^{2}$, Monica A. Valentovic, $\mathrm{PhD}^{3}$

\section{Author Affiliations:}

1. Joan C. Edwards School of Medicine, Huntington, West Virginia

2. University of Mississippi Medical Center, Jackson, Mississippi

3. Department of Biomedical Sciences Toxicology Research Cluster, Huntington, West Virginia

Source(s) of support: This work supported by the Robert C. Byrd Center for Rural Health, Marshall University. Funding for the Rural Health Initiative grant from the West Virginia Higher Education Policy Commission and the Marshall University School of Medicine Translational Research Pilot Grant.

Conflict of Interest declaration: Cottrell, Mitchell, Sangani, Thomas and Valentovic report no biomedical financial interests or potential conflicts of interest.

Previous Publications and/or presentations: There have been no prior publications, pending publications, or presentations

Statement of Purpose: To compare and correlate maternally reported rates of tobacco use to fetal cord blood levels of cotinine at the time of delivery. The rationale is to promote awareness of tobacco use during pregnancy in the tri-state region as discontinuation of smoking is a modifiable source of prenatal and perinatal morbidity and mortality

\section{Corresponding Author:}

Monica Valentovic, $\mathrm{PhD}$

Department of Biomedical Sciences Toxicology Research Cluster

Huntington, West Virginia

Email:Valentov@marshall.edu 


\section{Abstract}

The detrimental effects of cigarette use during pregnancy are well documented. Studies have shown that cigarette smoking while pregnant is associated with multiple adverse outcomes including pre-term birth, placental abruption, placenta previa, fetal growth restriction, stillbirth, increased rate of birth defects, and increased risk of sudden infant death syndrome. Cotinine is the primary metabolite of nicotine and allows for measurement of active as well as passive exposure. Cotinine freely crosses the placental barrier and maternal concentrations are closely correlated with newborn plasma levels. The aim of this study was to compare maternally reported rates of tobacco use to fetal umbilical cord blood cotinine levels at the time of delivery. A cross-sectional study was conducted on 172 patients. Patients were asked a single yes or no question in regards to their cigarette use during pregnancy. Cord blood was collected at the time of delivery and analyzed for serum concentrations of cotinine. Cotinine levels greater than 3.0 $\mathrm{ng} / \mathrm{mL}$ were considered consistent with the use of tobacco or tobacco cessation products. Maternal self-reporting of tobacco use indicates a reported tobacco use rate of $27.3 \%$ and an actual use rate of $30.2 \%$. The reported tobacco non-use rate was $72.7 \%$ and the actual non-use rate was $66.3 \%$. The prevalence of tobacco use during pregnancy in our study was $30.2 \%$, while the overall rate in the United States is reported to be $12.3 \%$. Our findings indicate that selfreported smoking prevalence and verified umbilical cord blood cotinine levels at the time of delivery have excellent correlation (kappa=0.76). Compared to the national average our study group also had nearly double the rate of tobacco use. Due to the deleterious effects of cigarette use during pregnancy continued efforts to educate patients regarding cigarette cessation is of utmost importance as cessation of tobacco products will improve and promote maternal and fetal well-being.

\section{Keywords}

cigarette, Appalachia, gravida, fetus, smoking, nicotine, cotinine

\section{Introduction}

The detrimental effects of cigarette use during pregnancy are well documented. Studies have shown that cigarette smoking is associated with multiple adverse outcomes during pregnancy including pre-term birth, placental abruption, placenta previa, fetal growth restriction, stillbirth, increased rate of birth defects, and increased risk of sudden infant death syndrome. ${ }^{1}$

The adverse effects of cigarette use extend beyond prenatal exposure. Nicotine is associated with adverse postnatal neurobehavioral, metabolic, cardiovascular, and respiratory outcomes, sudden infant death syndrome (SIDS) and childhood cancers. ${ }^{2-4}$ Nicotine is a neurological stimulant and considered a major contributor to the addictive effect of tobacco products. Cotinine is the primary metabolite of nicotine and allows for measurement of active as well as passive exposure. Cotinine freely crosses the placental barrier and maternal concentrations are strongly correlated with newborn plasma levels.,

Overall the rate of reported smoking during pregnancy in the United States has decreased from $18.4 \%$ in 1990 to $12.3 \%$ in 2010. ${ }^{7,8}$ However, in the Pregnancy Risk Assessment Monitoring System, Tong et al reported that West Virginia was one of three states where smoking prevalence 
increased between 1990-2010. ${ }^{8}$ The smoking prevalence in the state of West Virginia is $67 \%$ among adolescents between the age of 13-19 during the last 3 months of pregnancy. ${ }^{9}$

The aim of this study was to compare and correlate maternally reported rates of tobacco use to fetal cord blood levels of cotinine at the time of delivery among Appalachian gravidas. An additional objective was to examine the accuracy of self-reporting for smoking status in pregnant women. There is a lack of studies examining the frequency of tobacco use in Appalachia. The health effects of smoking are well recognized but discontinuation of smoking is a modifiable source of prenatal and perinatal morbidity and mortality. Identifying a higher than the national average frequency of tobacco usage supports the need to further educate the public regarding the adverse effects of smoking during pregnancy.

\section{Methods}

A cross-sectional study was conducted on 172 patients from April 2013 to February 2014. Inclusion criteria were consenting patients presenting to the labor and delivery unit at Cabell Huntington Hospital in active labor or admitted for induction of labor. Exclusion criteria were patients who delivered precipitously prior to being consented for the study. The study participants were asked a single yes or no question in regard to cigarette use during pregnancy. Cord blood was collected at the time of delivery and analyzed for serum concentrations of cotinine in $\mathrm{ng} / \mathrm{mL}$ by the Cabell Huntington Hospital laboratory.

For the purpose of this study cotinine levels greater than $3.0 \mathrm{ng} / \mathrm{mL}$ were considered consistent with the use of tobacco or tobacco cessation products. ${ }^{10}$ A serum cord blood cotinine level of $<3.0 \mathrm{ng} / \mathrm{mL}$ would classify a patient as a "non-tobacco user" and cotinine level of $>3.0 \mathrm{ng} / \mathrm{mL}$ would classify a patient as a "tobacco user". Self-reported maternal smoking data was collected at the time of admission and results were corroborated with cord blood analysis for cotinine. Demographic information was extracted from the subjects' electronic medical records.

Approval from the Institutional Review Board at Marshall University was obtained prior to beginning the study. Statistical analysis for continuous variables was by independent sample ttest using SAS Enterprise Guide 7.1. The project was supported by the Robert C. Byrd Center for Rural Health, Marshall University, and funding was obtained through the Rural Health Initiative grant from the West Virginia Higher Education Policy Commission and the Marshall University School of Medicine Translational Research Pilot Grant program.

\section{Results}

The overall prevalence of tobacco products in our study using a cotinine cutoff of $>3.0 \mathrm{ng} / \mathrm{mL}$ was $30.2 \%$ (Table 1). There were 41 patients who reported tobacco use whose cord cotinine levels were positive at $>3.0 \mathrm{ng} / \mathrm{mL}$ and 6 patients who reported tobacco use and cord cotinine levels were measured $<3.0 \mathrm{ng} / \mathrm{mL}$. There were 114 patients who denied tobacco use whose cord cotinine levels were negative and 11 patients who denied tobacco use while cord cotinine was $>3.0 \mathrm{ng} / \mathrm{mL}$. Comparing maternal reports of tobacco use indicates a reported tobacco use rate of $27.3 \%$ and an actual use rate as measured by cotinine in cord blood of $30.2 \%$. The reported tobacco non-use rate was $72.7 \%$ and the actual non-use rate was $66.3 \%$. 
Self-reported tobacco use showed excellent agreement with the cotinine levels measured in umbilical cord blood with a Cohen's kappa coefficient of 0.76 (0.61-0.80 is excellent agreement). ${ }^{11}$ In our study a single yes or no question in regard to maternal tobacco use has a sensitivity of $79 \%$, specificity of $95 \%$, positive predictive value of $87 \%$ and negative predictive value of $91 \%$.

Table 1: Correlation of maternal self-report and umbilical cord blood cotinine levels

\begin{tabular}{|l|l|l|l|}
\hline Maternal Self-Report & Cord Cotinine $>3.0 \mathrm{ng} / \mathrm{mL}$ & Cord Cotinine $<3.0 \mathrm{ng} / \mathrm{mL}$ & Total \\
\hline Yes & 41 & 6 & 47 \\
\hline No & 11 & 114 & 125 \\
\hline Total & 52 & 120 & 172 \\
\hline
\end{tabular}

Prevalence of tobacco use: $30.2 \%$

Sensitivity $79 \%$

Specificity $95 \%$

Positive Predictive Value $87 \%$

Negative Predictive Value 91\%

Kappa $=0.76(0.61-0.80 \text { is excellent agreement })^{11}$

Baseline characteristics were similar among our tobacco non-users and users for maternal age, BMI, race, urbanization, hemoglobin and hematocrit levels on admission, mode of delivery, estimated blood loss at the time of delivery, gestational age, hypertension, diabetes, and length of hospital stay (Table 2). Among the two groups there were no significant differences when comparing total pregnancies or pregnancy outcomes (term, preterm, abortions, living children). Maternal tobacco users were noted to be less likely to be married (17.3\% vs. 57.5\%), more likely to admit to substance abuse or dependence (26.92\% vs. $2.50 \%$ ), more likely to have Medicaid for insurance $(86.54 \%$ vs. $49.17 \%$ ), and more likely to be unemployed (73.08\% vs. $54.17 \%)$.

Table 2: Maternal Information. Reported mean \pm SD for continuous variables or $\mathrm{n}(\%)$ for categorical variables. 95\% Confidence Interval.

\begin{tabular}{|l|l|l|l|}
\hline & $\begin{array}{l}\text { Tobacco Non-User } \\
(\text { cotinine }<3 \mathrm{ng} / \mathrm{mL})\end{array}$ & $\begin{array}{l}\text { Tobacco User } \\
(\text { cotinine }>3 \mathrm{ng} / \mathrm{mL})\end{array}$ & $\mathrm{p}$-value \\
\hline Age & $25.92+5.53$ & $25.13+4.15$ & 0.31 \\
\hline BMI & $32.46+6.53$ & $30.46+7.77$ & 0.08 \\
\hline Cotinine Level (ng/mL) & $0.09+.34$ & $69.65+59.46$ & $<.0001$ \\
\hline Race & & & \\
\hline White & $113(94.17)$ & $51(98.08)$ & \\
\hline Other & $7(5.83)$ & $1(1.92)$ & \\
\hline Marital Status & & & \\
\hline Married & $69(57.5)$ & $9(17.31)$ & \\
\hline Other & $51(42.5)$ & $43(82.69)$ & \\
\hline
\end{tabular}




\begin{tabular}{|c|c|c|c|}
\hline $\begin{array}{l}\text { Self-Reported Substance } \\
\text { Abuse/Dependence }\end{array}$ & $3(2.50)$ & $14(26.92)$ & \\
\hline \multicolumn{4}{|l|}{ Urbanization } \\
\hline Urban & $63(52.5)$ & $30(57.69)$ & \\
\hline Rural & $57(47.5)$ & $22(42.31)$ & \\
\hline \multicolumn{4}{|l|}{ Insurance Type } \\
\hline Private & $57(47.5)$ & $5(9.62)$ & \\
\hline Medicaid & $59(49.17)$ & $45(86.54)$ & \\
\hline None & $4(3.33)$ & $2(3.85)$ & \\
\hline \multicolumn{4}{|l|}{ Employment } \\
\hline Employed & $55(45.83)$ & $14(26.92)$ & \\
\hline Not-Employed & $65(54.17)$ & $38(73.08)$ & \\
\hline $\begin{array}{l}\text { Mother Length of Hospital Stay } \\
\text { (days) }\end{array}$ & $3.76+3.84$ & $3.40+2.08$ & 0.44 \\
\hline Maternal Hypertension & $25(20.83)$ & $11(21.15)$ & \\
\hline Maternal Diabetes & $12(10)$ & $4(7.69)$ & \\
\hline Maternal Hemoglobin (g/dL) & $11.74+1.22$ & $11.87+1.23$ & 0.53 \\
\hline Maternal Hematocrit (\%) & $35.31+3.85$ & $35.84+3.46$ & 0.39 \\
\hline \multicolumn{4}{|l|}{ Mode of Delivery } \\
\hline Cesarean Delivery & $31(25.83)$ & $18(34.62)$ & \\
\hline Vaginal Delivery & 89 (74.17) & $34(65.38)$ & \\
\hline $\begin{array}{l}\text { Gestational Age at Delivery } \\
\text { (weeks) }\end{array}$ & $38.32+2.08$ & $38.48+1.91$ & 0.62 \\
\hline $\begin{array}{l}\text { Estimated Blood Loss at Time } \\
\text { of Delivery }(\mathrm{mL})\end{array}$ & $395.4+195.4$ & $423.8+229.2$ & 0.41 \\
\hline
\end{tabular}

Fetal outcomes were significantly different in regard to fetal weight, length of neonatal hospital stay, and neonatal intensive care unit admission (Table 3). Mean weight was $3311 \pm 65 \mathrm{~g}$ in the non-tobacco users and $3057 \pm 60$ in the tobacco users (mean \pm SD), with a p-value of 0.02 . This finding is consistent with previously published literature. ${ }^{1}$ Hospital length of stay for the infants was noted to be significantly different, with infants of tobacco non-users staying 5.08 \pm 9.62 days and infants of tobacco users staying $10.65 \pm 13.40$ (mean \pm SD), p-value of 0.009 . Infants born to tobacco users were also twice as likely to go to the NICU with $32.69 \%(n=17)$ of tobacco users and only $15.83 \%(n=19)$ of non-tobacco users infants being admitted to the unit.

Table 3: Fetal Information. Reported as mean \pm SD for continuous variables or $n(\%)$ for categorical variables. 95\% Confidence Interval.

\begin{tabular}{|l|l|l|l|}
\hline Gender & $\begin{array}{l}\text { Tobacco Non-User } \\
(\text { cotinine }<3 \mathrm{ng} / \mathrm{mL})\end{array}$ & $\begin{array}{l}\text { Tobacco User } \\
(\text { cotinine }>3 \mathrm{ng} / \mathrm{mL})\end{array}$ & p-value \\
\hline Male & $65(54.17)$ & $28(53.85)$ & \\
\hline Female & $55(45.83)$ & $24(46.15)$ & \\
\hline 1 Minute Apgar & $8.28 \pm 1.20$ & $8.31 \pm 0.88$ & 0.88 \\
\hline 5 Minute Apgar & $8.97 \pm 0.29$ & $8.85 \pm 0.46$ & 0.08 \\
\hline Birth Weight (grams) & $3311 \pm 65$ & $3057 \pm 60$ & $\mathbf{0 . 0 2}$ \\
\hline
\end{tabular}




\begin{tabular}{|l|l|l|l|}
\hline $\begin{array}{l}\text { Baby Length of Hospital Stay } \\
\text { (days) }\end{array}$ & $5.08 \pm 9.62$ & $10.65 \pm 13.40$ & $\mathbf{0 . 0 0 9}$ \\
\hline Head Circumference $(\mathrm{cm})$ & $33.99 \pm 3.62$ & $33.81 \pm 1.87$ & 0.67 \\
\hline Fetal Height $(\mathrm{cm})$ & $165.3 \pm 7.17$ & $165.6 \pm 7.01$ & 0.80 \\
\hline $\begin{array}{l}\text { Immediate Post-Partum } \\
\text { Location }\end{array}$ & & & \\
\hline \multicolumn{1}{|l|}{ Well-Born Nursery } & $101(84.17)$ & $35(67.31)$ & \\
\hline NICU & $19(15.83)$ & $17(32.69)$ & \\
\hline
\end{tabular}

\section{Discussion}

West Virginia currently ranks first in United States with 27 of every 100 adults being tobacco users. $^{12,13}$ A recent report indicated that $67 \%$ of West Virginia pregnant adolescents 19 years of age or younger smoked during the last 3 months of pregnancy. ${ }^{9}$ Overall the rate of reported smoking during pregnancy in the United States is $12.3 \% .^{7,8}$ Our study indicates that smoking prevalence (based on a cotinine level of $>3.0 \mathrm{ng} / \mathrm{mL}$ ) at the time of delivery among Appalachian gravidas was $30.2 \%$. These findings indicate that self-reported smoking prevalence and verified umbilical cord blood cotinine levels at the time of delivery were much higher than the national average in the United States. Our study is the first to correlate umbilical cord cotinine levels in babies born in West Virginia with self reported smoking habit of the mothers during pregnancy.

The results of our study are consistent with previous inquires examining self-reported tobacco use among pregnant women and the correlation with serum concentrations of cotinine. A study of 448 women using a maternal serum cotinine concentration of $>10.0 \mathrm{ng} / \mathrm{mL}$ to define tobacco users determined that $94.9 \%$ of women who denied smoking and $87.0 \%$ of women who stated they smoked reported their status accurately (kappa=0.83). ${ }^{14}$ Kvalvik et al studied a subsample of 2,997 women in the Norwegian Mother and Child Cohort Study (MoBa) to assess selfreported tobacco use and plasma cotinine concentrations at 18 weeks gestational age using a cutoff of $12 \mathrm{ng} / \mathrm{mL} .{ }^{15}$ The sensitivity and specificity for self-reported smoking was $82 \%$ and $99 \%$ respectively. In our study a cotinine level of $3.0 \mathrm{ng} / \mathrm{ml}$ or higher was considered positive for exposure to tobacco usage and this value was based on a previous report by another laboratory. ${ }^{10}$ This cutoff was adopted for our study as our mothers were of different races and the lower level will include individuals that occasionally smoke. Cotinine levels resulting from exposure to second-hand smoke has declined over the past 30 years due to increased smoke free public areas. Cotinine levels in nonsmokers exposed to second-hand smoke are less than $1 \mathrm{ng} / \mathrm{ml} ;{ }^{10}$ it is unlikely that second-hand smoke exposure was identified as a smoker in our study as our cutoff level was $3.0 \mathrm{ng} / \mathrm{ml}$.

Intervention strategies to promote cessation of tobacco use, prevent relapse, and avoid secondhand smoke exposure are essential and should be incorporated during routine prenatal visits. ${ }^{16}$ Techniques for intervention range from counseling, cognitive and behavioral therapy, hypnosis, acupuncture to pharmacologic therapy. ${ }^{17,18}$ Each method may have a different effect and outcome, so it is important to individualize the approach for each patient and provide the risks and benefits that are associated with each option. Smoking cessation prior to 15 weeks gestation has been shown to provide the greatest benefits for both the fetus and the mother, however, cessation of smoking at anytime during the pregnancy has shown to be beneficial. ${ }^{19,20}$ 
In fact, cessation prior to the third trimester can offer a significant reduction in the low birth weight that is caused by maternal smoking. ${ }^{20}$

This study does have limitations. The self-reported daily amount of cigarettes smoked was obtained however it was not ascertained when the study participants last had a cigarette prior to presenting to the labor and delivery unit. Perhaps this could be a contributing factor to our patients who reported using tobacco products but the resultant umbilical cord blood for cotinine was negative. Another contributing factor could be innate differences in regard to the fetal metabolism of nicotine and its metabolite cotinine that was measured for this study. Further studies are needed in the area of fetal metabolism of tobacco products. There was also the potential for selection bias as all patients who presented to the labor and delivery unit were not enrolled in the study.

In our study of Appalachian gravidas self-reported smoking prevalence and verified umbilical cord blood cotinine levels at the time of delivery have excellent correlation. Compared to the national average our study group also had nearly double the rate of tobacco use. Due to the deleterious effects of cigarette use during pregnancy continued efforts to educate patients regarding cigarette cessation is of utmost importance as cessation of tobacco products will improve and promote maternal and fetal well-being. 


\section{References}

1. The Health Consequences of Smoking: A Report of the Surgeon General. Reports of the Surgeon General. Atlanta (GA)2004.

2. Bruin JE, Gerstein HC, Holloway AC. Long-term consequences of fetal and neonatal nicotine exposure: a critical review. Toxicol Sci. 2010;116(2):364-74.

3. Cornelius MD, Day NL. Developmental consequences of prenatal tobacco exposure. Curr Opin Neurol. 2009;22(2):121-5.

4. Heck JE, Contreras ZA, Park AS, Davidson TB, Cockburn M, Ritz B. Smoking in pregnancy and risk of cancer among young children: A population-based study. Int J Cancer. 2016;139(3):613-6.

5. Berlin I, Heilbronner C, Georgieu S, Meier C, Spreux-Varoquaux O. Newborns' cord blood plasma cotinine concentrations are similar to that of their delivering smoking mothers. Drug Alcohol Depend. 2010;107(23):250-2.

6. Laskowska-Klita T, Chelchowska M, Leibschang J. [Concentrations of cotinine in serum and urine of smoking pregnant women and in placenta and umbilical cord blood]. Przegl Lek. 2005;62(10):1007-9.

7. Tong VT, Dietz PM, Morrow B, D'Angelo DV, Farr SL, Rockhill KM, et al. Trends in smoking before, during, and after pregnancy--Pregnancy Risk Assessment Monitoring System, United States, 40 sites, 2000-2010. MMWR Surveill Summ. 2013;62(6):1-19.

8. Tong VT, Jones JR, Dietz PM, D'Angelo D, Bombard JM, Centers for Disease C, et al. Trends in smoking before, during, and after pregnancy - Pregnancy Risk Assessment Monitoring System (PRAMS), United States, 31 sites, 2000-2005. MMWR Surveill Summ. 2009;58(4):1-29.

9. Ahmadi-Montecalvo H, Haile ZT, Umer A, Chertok IR. Adolescent Pregnancy and Smoking in West Virginia: Pregnancy Risk Assessment Monitoring System (PRAMS) 2005-2010. Matern Child Health J. 2016.

10. Benowitz NL, Bernert JT, Caraballo RS, Holiday DB, Wang J. Optimal serum cotinine levels for distinguishing cigarette smokers and nonsmokers within different racial/ethnic groups in the United States between 1999 and 2004. Am J Epidemiol. 2009;169(2):236-48.

11. Viera AJ, Garrett JM. Understanding interobserver agreement: the kappa statistic. Fam Med. 2005;37(5):360-3.

12. Nguyen KH, Marshall L, Brown S, Neff L. State-Specific Prevalence of Current Cigarette Smoking and Smokeless Tobacco Use Among Adults - United States, 2014. MMWR Morb Mortal Wkly Rep. 2016;65(39):1045-51.

13. Agaku IT, King BA, Dube SR, Centers for Disease C, Prevention. Current cigarette smoking among adults - United States, 2005-2012. MMWR Morb Mortal Wkly Rep. 2014;63(2):29-34.

14. Klebanoff MA, Levine RJ, Clemens JD, DerSimonian R, Wilkins DG. Serum cotinine concentration and self-reported smoking during pregnancy. Am J Epidemiol. 1998;148(3):259-62.

15. Kvalvik LG, Nilsen RM, Skjaerven R, Vollset SE, Midttun O, Ueland PM, et al. Self-reported smoking status and plasma cotinine concentrations among pregnant women in the Norwegian Mother and Child Cohort Study. Pediatr Res. 2012;72(1):101-7.

16. Force USPST. Counseling and interventions to prevent tobacco use and tobacco-caused disease in adults a nd pregnant women: U.S. Preventive Services Task Force reaffirmation recommendation statement. Ann I ntern Med. 2009;150(8):551-5.

17. Committee opinion no. 471: Smoking cessation during pregnancy. Obstet Gynecol. 2010;116(5):1241-4.

18. Committee on Health Care for Underserved W. Committee opinion number 503: tobacco use and women's health. Obstet Gynecol. 2011;118(3):746-50.

19. McCowan LM, Dekker GA, Chan E, Stewart A, Chappell LC, Hunter M, et al. Spontaneous preterm birth and small for gestational age infants in women who stop smoking early in pregnancy: prospective cohort study. BMJ. 2009;338:b1081.

20. England LJ, Kendrick JS, Wilson HG, Merritt RK, Gargiullo PM, Zahniser SC. Effects of smoking reduction during pregnancy on the birth weight of term infants. Am J Epidemiol. 2001;154(8):694-701. 